\title{
Designing Microstrip Low Pass Filter In ISM Band For Rectenna System
}

\author{
Pavan Kumar Sharma, Veerendra Singh Jadaun, Devesh Kumar Mahor and \\ Atal Verma
}

Research Scholar Department of Electronics Engg. Madhav Institute of Technology and Science Gwalior-05 (M.P.) India E-mail: sharmapavan.0511@gmail.com, veermtech@gmail.com, deveshmahor9@gmail.com, atalverma65@gmail.com

\begin{abstract}
The filter is required in all RF-communication techniques. Low Pass Filters play an important role in wireless power transmission systems. Transmitted and received signals have to be filtered at a certain frequency with a specific bandwidth. In this paper the design of filter is done in the ISM (Industrial, Scientific and Medical) band whose frequency lies between $1.55 \mathrm{GHz}-3.99 \mathrm{GHz}$. After getting the specifications required, we realized the filter structure with the help of CST-MW software.
\end{abstract}

Keywords: Low Pass Filter (LPF), Rectenna, Stripline and Microstrip line, CSTMW, Loss tangent.

\section{Introduction}

The passive $(L C)$ filters work quite well at frequencies up to a few hundred megahertz. Beyond this range, components deviate significantly from anything close to ideal. The microwave filters are based on distributed parameters rather than lumped inductors and capacitors [1]. For low-power applications, stripline and microstrip filters are extensively used because of their low cost and repeatability. For high-power requirements, waveguide structures are utilized [2]. Microstrip line is bimetallic which contain two metallic surface separated with a small distance, having a dielectric material between them. There are one metallic surface having the filter geometry and other surface having the ground plane at which the reflection of wave is occurs. 
Richards' transformation is use for realizing the filter the conversion of lumped element filters into distributed filters [2]. In this the short and open circuited transmission line stubs are use having the length of the order of $\lambda / 4$ or $\lambda / 8$. Kuroda's identities are also use in realization of filter, it allow the transformation of series stubs into shunt stubs and vice versa [3]. This is an exact transformation and not an approximation. For obtaining the better results of filter combination of both techniques as described previous is used.

The image parameter method and insertion loss method are use for analysis of filter. Binomial or Butterworth response is used to characterize the maximally flat filter Chebyshev polynomial synthesis is use for equal ripple response filter [1].

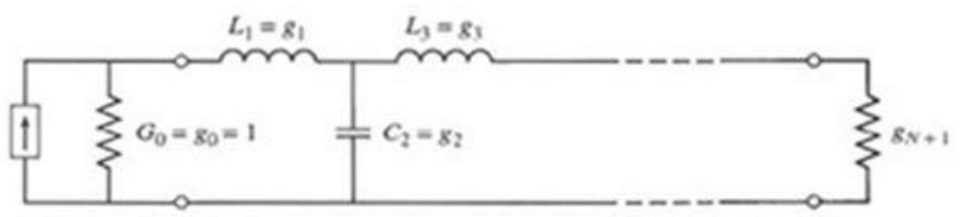

Fig. 1: Ladder circuit for low-pass filter prototype beginning with a series element

\section{Wireless Power Syatem}

The primary components of Wireless Power Transmission are Microwave Generator, Transmitting antenna and Receiving antenna (Rectenna) [4].

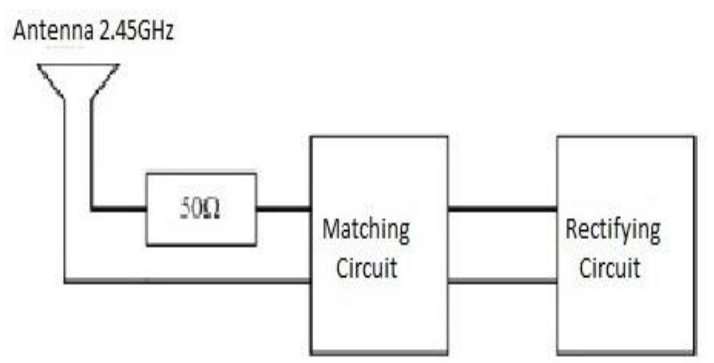

Fig 2: The diagram of rectenna circuit

The rectenna is a passive element consists of antenna, rectifying circuit with a low pass filter between the antennas and rectifying diode. Schottky barrier diodes (GaAs-W, Si, and GaAs) are usually used in the rectifying circuit due to the faster reverse recovery time and much lower forward voltage drop and good RF characteristics. The rectenna efficiency for various diodes is different for different frequency [4]. 


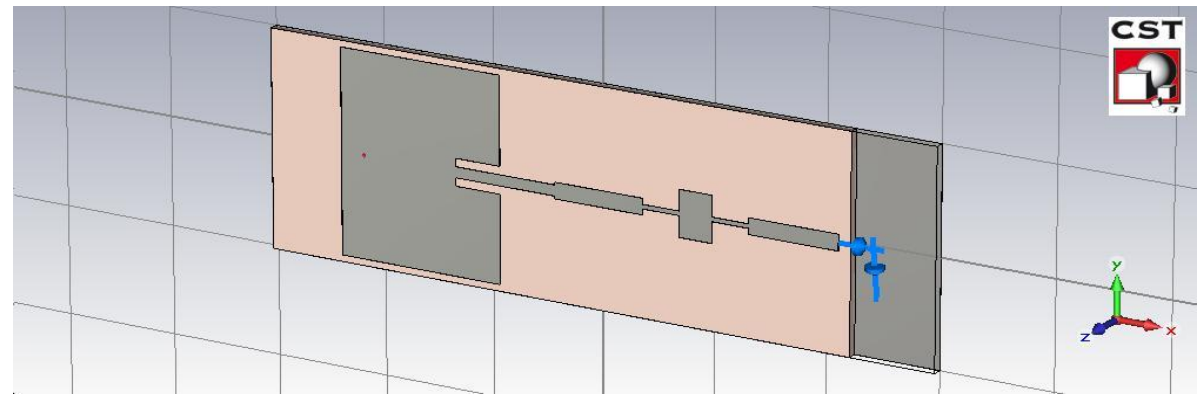

Fig.3: Simulated circuit of Rectenna heaving Antenna+ Filter+ Rectifier

The above figure shows the Rectenna system heaving the antenna, filter and rectifier; it is use for receiving the wireless power. The wireless signal received by antenna is filtered in LPF the higher order harmonics are remove after filtering. After the LPF a rectifier is connected following by the load. The output voltage is measured across this load element. The proposed filter is used in this rectenna system.

\section{Designing of Filter}

The design of microstrip lowpass filters involves two main steps. The first one is to select an appropriate lowpass prototype, The choice of the type of response, including passband ripple and the number of reactive elements, will depend on the required specifications. The element values of the lowpass prototype filter, which are usually normalized to make a source impedance $g 0=1$ and a cutoff frequency $\Omega c=1.0$, are then transformed to the L-C elements for the desired cutoff frequency and the desired source impedance, which is normally $50 \mathrm{ohms}$ for microstrip filters. The next main step in the design of microstrip lowpass filters is to find an appropriate microstrip realization that approximates the lumped element filter [2][6].

In order to illustrate the design procedure for this type of filter, the design of a three-pole LPF is described in follows.

The filter design steps are as follows:

Order of filter $\mathrm{N}=3$

Relative Dielectric Constant $\varepsilon r=4.3$

Height of substrate, $\mathrm{h}=1.6 \mathrm{~mm}$

The loss tangent $\tan \delta=0.02$

The highest line impedance $\mathrm{ZH}=\mathrm{ZOL}=93 \Omega$

The lowest line impedance $\mathrm{ZL}=\mathrm{ZOC}=24 \Omega$

Normalized cutoff $\Omega c=1.0$

Cutoff frequency $f c=2.45 \mathrm{GHz}$

Passband riple $0.1 \mathrm{~dB}$ (or return loss $\leq-16.42 \mathrm{~dB}$ )

The filter Source/load impedance $Z 0=50 \mathrm{ohms}$ 


\section{Calculation of the Dimensions of the Filter}

A lowpass prototype with Chebyshev response is chosen, whose element values are given as below taken from the Table3.2 [1] with passband ripple $\mathrm{L}_{\mathrm{Ar}}=0.1 \mathrm{~dB}$ for $\mathrm{N}=3$.

$g 0=g 4=1$

$g 1=g 3=1.0316$

$g 2=1.1474$

For the normalized cutoff $\Omega c=1.0$. Using the element transformations we have

$$
\begin{aligned}
& L 1=L 3=\frac{Z_{0}}{\mathrm{go}} \frac{\Omega c}{2 \mathrm{nfc}} g 1=3.3507 \times 10^{-9} \mathrm{H} \\
& C 2=\frac{\mathrm{g}}{Z_{0}} \frac{\Omega c}{2 \mathrm{nfc}} g 2=1.4907296 \times 10^{-12} \mathrm{~F}
\end{aligned}
$$

After calculating the value of inductance and capacitance, it is the second step to finding the other parameter with the help of formulae [1]-[3]. After finding these values the results are tabulated below.

Table. 1 Filter design parameters at $2.45 \mathrm{GHz}$ with $\mathrm{L}_{\mathrm{Ar}}=0.1 \mathrm{~dB}$

\begin{tabular}{|c|l|c|c|c|}
\hline $\begin{array}{c}\text { S. } \\
\text { No. }\end{array}$ & Parameter & $\begin{array}{c}\text { Matching } \\
\text { Section }\end{array}$ & $\begin{array}{c}\text { Inductor } \\
\text { section }\end{array}$ & $\begin{array}{c}\text { Capacitor } \\
\text { section }\end{array}$ \\
\hline 1. & $\begin{array}{l}\text { Characteristic } \\
\text { Impedance }\end{array}$ & $\mathrm{Z}_{0}=50 \Omega$ & $\mathrm{Z}_{0 \mathrm{~L}}=93 \Omega$ & $\mathrm{Z}_{0 \mathrm{C}}=24 \Omega$ \\
\hline 2. & $\begin{array}{l}\text { Effective } \\
\text { Dielectric } \\
\text { Constant }\end{array}$ & $\varepsilon_{\text {reffZ }}=3.332485$ & $\varepsilon_{\text {reffL }}=2.983417$ & $\varepsilon_{\text {reffC }}=3.640488$ \\
\hline 3. & $\begin{array}{l}\text { Width of } \\
\text { Microstrip } \\
\text { Line }\end{array}$ & $\mathrm{W}_{\mathrm{Z}}=2.99438 \mathrm{~mm}$ & $\mathrm{~W}_{\mathrm{L}}=0.847290 \mathrm{~mm}$ & $\mathrm{~W}_{\mathrm{C}}=8.708496 \mathrm{~mm}$ \\
\hline 4. & $\begin{array}{l}\text { Length of } \\
\text { Microstrip } \\
\text { Line }\end{array}$ & $\mathrm{Z}_{\mathrm{l}}=16.76914 \mathrm{~mm}$ & $\mathrm{l}_{\mathrm{L}}=6.633275 \mathrm{~mm}$ & $\mathrm{l}_{\mathrm{C}}=5.95740 \mathrm{~mm}$ \\
\hline 5. & Wavelength & $\lambda_{\mathrm{o}}=67.7215 \mathrm{~mm}$ & $\lambda_{\mathrm{L}}=17.72303 \mathrm{~mm}$ & $\lambda_{\mathrm{C}}=64.1764 \mathrm{~mm}$ \\
\hline
\end{tabular}

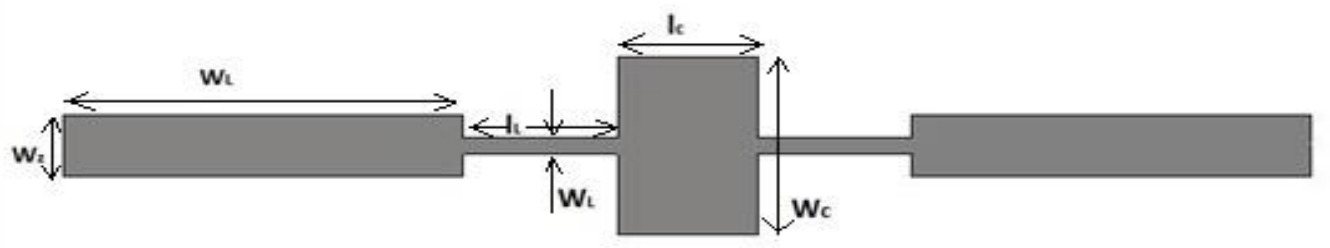

Fig.4: Geometric view of low-pass filter (LPF) of ISM band 


\section{Simulation Result of Lowpass Filter}

For the simulation purpose CST-MW [9] solver is used which is work in transient domain. When the LPF is simulated in the frequency range of $0-5 \mathrm{GHz}$, The following plot shows the S-parameters and smith chart as a function of frequency. It can see that the higher frequency band is attenuated beyond the ISM band only low frequency components of RF-signals are passed.

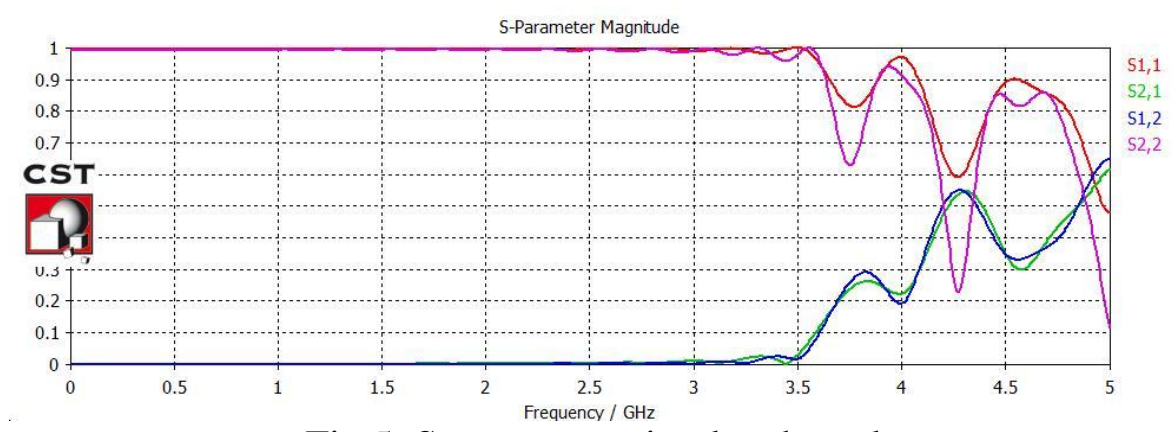

Fig.5: S-parameter simulated result
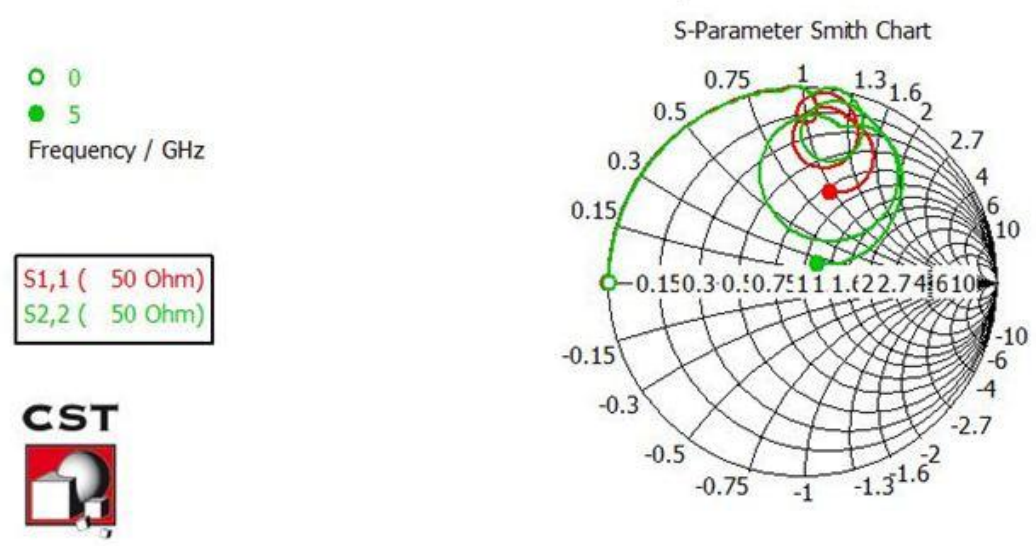

Fig.6: Smith chart of the filter

\section{Applications}

The filters are one of the primary and important components of a microwave power transmission system [7][8]. Low pass filter must be included at the transmitting end and the receiving side of the system to get desired spectrum and is use to remove the higher order harmonic of the central frequency. We have designed microstrip low pass filter because it takes less space than a similar low pass filter using stubs. Its compact nature minimizes required space for realization and is suitable for integration within Wireless system; it is use in satellite communication and combines with antenna in the missile as military services [5][6]. 


\section{Conclusion}

After the whole analysis the proposed Lowpass filter is designed with a satisfactory parameter and is operated in the ISM band for using the Wireless power reception system. In this paper the designing of LPF and its parameters are tabulated. The simulation and application of the filter are described.

\section{References}

[1] Jia-Sheng Hong; M. J. Lancaster. Microstrip Filters for RF/Microwave Applications Copyright (C) 2001 John Wiley \& Sons, Inc. ISBNs: 0-47138877-7 (Hardback); 0-471-22161-9 (Electronic)

[2] Pozar David M. (1998). Microwave Engineering 2nd Edition, USA: John Wiley \&Sons, Inc.

[3] Ludwig; Reinhold and Bretchko; Pavel(2000) RF Circuit Design - Theory and Application. New Jersey, USA: Prentice-Hall,Inc.

[4] S. Sheik Mohammed; K. Ramasamy; T. Shanmuganantham. Wireless Power Transmission-A Next Generation Power Transmission System. International Journal of Computer Applications (0975-8887) Vol. 1-No. 13, 2010 pp.100103.

[5] Constantine A Balanis. Antenna Theory, Analysis and Design. $2^{\text {nd }}$ Edition, John Wiley, New York, 1998

[6] Veerendra Singh Jadaun; Pavan Kumar Sharma; Hemant Kumar Gupta; Devesh Kumar Mahor. "Design a Microstrip Band Pass Filter for 6GHz". Science Publishing Cooperation Journal name International Journal of Engineering and Technology (IJET) in Vol.1 No.3 2012 pp.217-222.

[7] W. W. Mumford. Tables of stub admittances for maximally flat filters using shorted quarter-wave stubs. IEEE Trans.Microwave Theory Tech., vol. 13, pp.373-376, Dec. 1965.

[8] Pavan Kumar Sharma; Hemant Kumar Gupta; Veerendra Singh Jadaun; Ritesh Kumar Tambulkar. "Sierspinski Carpet Microstrip Patch Antenna for Wireless Communication in ISM band at 2.45GHz." International Conference E-Manthan-2012 at SRGI Jhansi pp.317-319.

[9] http://www.cst.com/content/products/mws/overview.aspx (c) 2012 CST Computer Simulation Technology AG. 